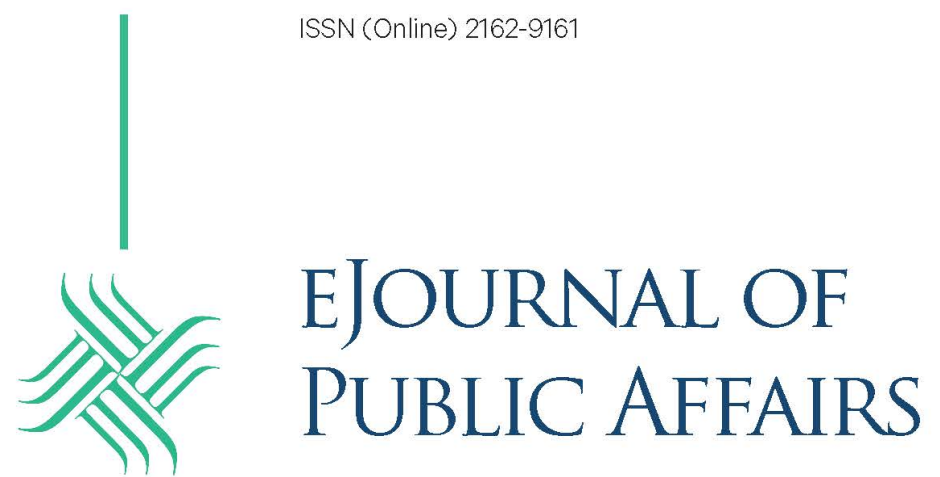

VOLUME 8 | ISSUE 3

\title{
Institutionalizing Community Engagement: The College Within a University as a Missing Organizational Link
}

\author{
John Saltmarsh \\ University of Massachusetts Boston \\ Michael Middleton \\ Hunter College \\ Melissa Quan \\ Fairfield University
}

\footnotetext{
Author Note

John Saltmarsh, Department of Leadership in Education, University of Massachusetts Boston; Michael Middleton, School of Education, Hunter College; Melissa Quan, Center for Faith and Public Life, Fairfield University.

Correspondence regarding this article should be addressed to John Saltmarsh, Professor of Higher Education, College of Education and Human Development, University of Massachusetts Boston. E-mail: john.saltmarsh@umb.edu
} 


\begin{abstract}
This article examines organizational change that can be implemented at the level of a college in a university in order to institutionalize community-engaged scholarship as a core value of the college. Through the development and implementation of an assessment rubric, the authors argue that college-level institutionalization of community-engaged scholarship can be evaluated as a complement to department- and institution-level efforts. Attention to college-level engagement offers new possibilities for deeper institutionalization of community-engaged scholarship.
\end{abstract}

Keywords: community engagement, higher education, organizational change 
Institutionalizing Community Engagement: The College Within a University as a Missing Organizational Link

Increasingly, universities are called upon to mobilize their intellectual and human capacity to address needs in their communities and beyond. While the creation of a campus-wide coordinating infrastructure designed to facilitate community engagement is critical, it is important to account for the significant variation in, and quality of, community engagement that exists across units of a university. Arguably, a college/school within a university should be developed as the locus of faculty and student engagement. Colleges or schools within a university often have their own well-developed missions and goals that embrace community engagement; can be seen as labs for trying new ideas, pathways, or strategies for engagement; and have their own natural disciplinary base within the community for engagement. Drawing on a review of the literature, the study discussed in this article examined organizational components at the college level that support community engagement and contribute to the creation of a culture of engagement in a college. Based on the literature review and the practical experiences of the authors, an organizational assessment rubric for supporting and rewarding communityengaged scholarship was designed and piloted with four colleges at four separate research universities for the purposes of self-assessment and strategic planning.

\section{Literature Review}

While there is a wealth of literature on institutionalizing community engagement in higher education (Furco \& Miller, 2009; Moore \& Ward, 2010; Saltmarsh et al., 2009; Sandmann, Thornton, \& Jaeger, 2009; Warnick, 2007; Weerts \& Sandmann, 2008; Wergin, 2006) and, more specifically, in an academic department (Aminzade, 2004; Battistoni, 2003; Kecskes, 2006; Saltmarsh \& Gelmon, 2006), little research has focused on institutionalizing community engagement in a college/school within a university (Dana \& Emihovich, 2004). This study contributes to the literature on institutionalizing community engagement in a college/school at a research university.

In the context of this study, community engagement refers to relationships that connect the intellectual resources of the college with knowledge resources outside the college that are grounded in the qualities of reciprocity, mutual respect, shared authority, and co-creation of goals and outcomes. Such relationships are by their very nature transdisciplinary (relating to knowledge that transcends the disciplines and the college) and asset-based (relating to valid and legitimate knowledge that exists outside the college). Transdisciplinary and asset-based frameworks and approaches impact both pedagogy and scholarship. They also inform an organizational logic such that colleges need to change their policies, practices, structures, and culture in order to enact engagement and support scholars involved in community-engaged teaching, learning, and knowledge generation.

This framing of community engagement aligns with the definition provided by the Carnegie Foundation for its Community Engagement Classification:

Community engagement describes the collaboration between institutions of higher education and their larger communities (local, regional/state, national, global) for the mutually beneficial exchange of knowledge and resources in a context of partnership and reciprocity. 
The purpose of community engagement is the partnership of college and university knowledge and resources with those of the public and private sectors to enrich scholarship, research, and creative activity; enhance curriculum, teaching and learning; prepare educated, engaged citizens; strengthen democratic values and civic responsibility; address critical societal issues; and contribute to the public good. (Brown University, n.d.)

The Carnegie Community Engagement Classification focuses on institution-wide assessment, whereas the college-level self-assessment rubric is aimed more specifically at an academic unit; therefore, there is particular emphasis on the core academic activities of teaching and learning and research, and on faculty, deans, and chairs. For many colleges, the academic culture and the incentives for faculty conveyed through that culture emphasize the importance of research and creative activity.

Drawing on the literature and current practice (Doberneck et al., 2010; Ellison \& Eatman, 2008; Gurgevich et al., 2003; Hyman et al., 2002; Stanton, 2008, 2012; Tulane University, 2013), for the purposes of this project and article, we focus on a definition of communityengaged scholarship (CES) characterized by creative intellectual work based on a high level of professional expertise, the significance of which peers can validate and which enhances the fulfillment of the mission of the campus/college/department. Community-engaged scholarship is not considered to be synonymous with community-engaged research and can be demonstrated in teaching, research, and creative activities, as well as in service. Scholars who practice CES often do so within institutional contexts in which standards and incentives for career advancement have not kept pace with changes in knowledge production and dissemination. As a result, many campuses are reconsidering and revising reward structures to recognize new forms of scholarship, including CES (O’Meara, Eatman, \& Peterson, 2015).

As with departments, colleges or schools are "where tensions arise about publicly engaged scholarship at the point of promotion and tenure. They are where all the work of promotion gets done and where the potential for real change is greatest" (Ellison \& Eatman, 2008, p. v). Further, Holland (2009) pointed out that, in a large research university, it might be easier to start institutionalization with a small unit, like a college/school. Some scholars believe that a more local, place-based approach is crucial to sustaining community engagement in higher education because it can demonstrate for stakeholders the relevance of disciplinary knowledge to communities (Kecskes, 2006, Saltmarsh et al., 2009; White, 2016).

A quarter century of practice and a significant body of literature has contributed to an understanding of the kinds of infrastructure needed to advance community engagement at the institutional or campus level. We drew on that practice and literature, adapting it (1) for the unique context of a college/school within a university, and (2) to support community-engaged scholarship, not community engagement writ large. Therefore, the kind of support discussed here focuses on supporting and advancing the work of scholars (with a particular focus on faculty and graduate students), staff, administrators, and community partners involved in generating CES. Regarding faculty, the focus is on faculty scholarship and their scholarly roles in teaching and learning and in service, to extent that, for many community-engaged scholars, those faculty roles are closely interwoven and integrated. The literature also points to the need to integrate CES into graduate studies in order to prepare and socialize the next generation of community-engaged scholars (Aminzade, 2004; Ellison \& Eatman, 2008; Moore \& Ward, 2010; O’Meara, 2016). We 
focus our attention on the academic culture of the college, namely policies related to faculty rewards, a key artifact of culture, and, more specifically, promotion and tenure.

As Tierney and Perkins (2015) observed,

the professional reward structure needs to shift. Institutions need a diversity of routes to academic excellence and some of them will pertain to being involved outside the ivory tower... Academic work needs to have an impact in order to provide society's return on investment.... For that to happen, the reward structure and those practices that socialize faculty need to shift in a way that supports engagement rather than disdains it. (p. 186)

In 2008, Imagining America - a network of colleges, universities, and community partners dedicated to publicly engaged scholarship, particularly in the arts, humanities, and designproduced a report, Scholarship in Public: Knowledge Creation and Tenure Policy in the Engaged University, based on a series of structured interviews with over 30 publicly engaged scholars who included faculty, deans, department chairs, provosts, presidents, and center directors. The report outlined a set of recommendations that serve as a road map for colleges and universities interested in creating institutional, cultural, and policy change to support CES. The report's recommendations focusing on faculty rewards and academic culture include: (1) defining CES; (2) creating policy based on a continuum of scholarship that equally values traditional scholarship and CES; (3) recognizing indicators of excellence in CES, specifically interdisciplinarity, intercultural engagement, impact in multiple arenas, and integration across key areas of faculty work (i.e., teaching, research, and service); (4) recognizing a broad range of scholarly artifacts that count (i.e., beyond scholarly journal publications); (5) creating guidelines that can be used by tenure applicants and reviewers to clarify what qualifies as evidence of CES; (6) providing professional development on how to present CES in professional portfolios; (7) recognizing community partners as peers in peer review; (8) creating a pathway for junior faculty and graduate students interested in CES; and (9) creating specific guidelines for promoting community-engaged scholars to the level of full professor.

On some campuses, leaders are working with faculty to revise faculty reward policies. For example, at Syracuse University, with strong administrative leadership and faculty commitment, the faculty and administration engaged in a five-year process that led to a revision of the promotion and tenure guidelines, resulting in language that explicitly incorporates community engagement into the reward policies of the campus (Syracuse University, n.d.). Similarly, in its Academic Plan 2011, the University of North Carolina at Chapel Hill (UNCChapel Hill) set forth the strategic priority of building engaged scholarship into the core culture of the campus and throughout all academic units through the revision of promotion and tenure policies.

The vision of CES emerging within a college/school can inspire action, but it is unlikely that such a vision alone will produce an action plan aligned with the core functions and organizational features of that college/school. In considering how to implement an actionable plan within a college/school of a university, we used our experience as university faculty and staff and as an administrator, as well as the emergent literature, to identify key structural components of a college/school that can contribute to fostering CES. We sought feedback from colleagues with expertise in CES and deep understanding of universities to identify components at similar levels of importance that are clearly distinguished from one another and that play a key 
role in advancing a vision for CES within a college/school. The following sections detail a set of areas that the literature suggests are essential to institutionalizing community engagement.

\section{Literature on Institutionalizing Community Engagement}

Mission, vision, and leadership. Developing a mission and vision for community engagement is tied directly to leadership and direction. A review of successful Carnegie Community Engagement Classification applications points to the need for more attention to the development of clear community engagement definitions and strategic plans designed specifically for engagement (Holland, 2009). Others have pointed to the importance of creating clear definitions of CES that are aligned across academic units, from departments to colleges or schools to the university as a whole (Crookes, Else, \& Smith, 2015; Dana \& Emihovich, 2004; Kecskes, 2006; O'Meara, Sandmann, Saltmarsh, \& Giles, 2011).

Leadership support for the institutionalization of CES and the personal engagement of leaders is essential (Holland, 2009; Sandmann \& Plater, 2009). Sandmann and Plater (2009) identified four stages of engaged leadership: "(1) interpreting institutional mission to reflect engagement with communities...; (2) defining specific objectives and goals to implement the mission; (3) articulating the means and priorities for taking action; and (4) manifesting commitment through personal interaction" (p. 15). Dana and Emihovich (2004) emphasized the importance and power of seizing the right moment to advance community engagement, having a clearly articulated vision, and creating rituals to mark and celebrate CES.

Community engagement can be fragile if a single, often transient, leader (e.g., president, chancellor, provost) is associated with a commitment to campus engagement. Leaders need to foster the capacity of others across the campus, including building CES into job descriptions and establishing a wider community of engagement (Moore \& Ward, 2010).

Visibility and communication. A significant component of the foundational indicators section of the Carnegie Community Engagement Classification application requires campuses to document how community engagement is made visible through key communication functions, from campus websites to press releases to presidential addresses. Reflecting on the institutionalization of CES in the College of Education at the University of Florida, for instance, Catherine Emihovich noted that she never missed an opportunity to talk about CES in public addresses and written documents (Dana \& Emihovich, 2004). This helped to catalyze conversations and raise awareness about CES. Further, a rhetoric of community engagement helps scholars feel supported even when policies are lacking (Moore \& Ward, 2010). Likewise, Emihovich reflected on the value of creating cultural markers through awards and signature events to celebrate CES (Dana \& Emihovich, 2004).

Other critical opportunities for increasing the visibility of CES include student recruitment, admissions materials and criteria, and faculty and staff recruitment and hiring materials such as job announcements and descriptions (Dana \& Emihovich, 2004; Ellison \& Eatman, 2008).

Recognition. Recognition for CES is an important dimension for creating a culture of engagement. We make a distinction between recognition and rewards since, as we argue, recognition cannot and should not be a substitute for rewards, and recognition is associated with making visible and celebrating CES in public ways. On the first point, there is a tendency for campuses that are working to advance community engagement to create a set of recognition 
possibilities, such as annual awards, that are relatively easy to achieve and to put off or avoid revising reward policies, which is a much more difficult task. Similarly, recognition can come in the form of making CES count in annual faculty reports, which are often tied to merit pay increases. These, too, are tangible and more public forms of recognition that can complement, but are not substitutes for, faculty rewards.

While recognition can take many forms, a few of the most common and impactful can be centered within the college/school, allowing more people across a campus to be recognized. Since most faculty relationships are formed within their academic units, recognition at this level is often more personal and creates more of a culture of support for CES work within existing working relationships. Some ways this recognition can occur include funding (e.g., seed funds to catalyze and support CES; Aminzade, 2004; Dana \& Emihovich, 2004; Moore \& Ward, 2010); awards and celebrations for CES (Dana \& Emihovich, 2004); and clear documentation of CES in annual merit reviews (O’Meara, 2016). Taken together, these forms of recognition increase the visibility of CES, bring legitimacy to the work, help foster a community of scholars, and promote equality through rewards and recognition (Crookes, Else, \& Smith, 2015; Moore \& Ward, 2010).

Policies related to faculty work. Rewards are the policies and criteria that constitute what is valued in the core academic culture of the unit, in this case a college/school. Policies are artifacts of culture and often underpin what happens organizationally behind the scenes. In crafting policies supportive of CES, college/school leadership teams should consider a set of guiding questions. For instance, what are the criteria for promotion and tenure, and do the criteria specifically articulate CES as core academic work - that is, as research and teaching, and not singly as service or outreach? Is there a culture among the faculty such that the policies are enacted in ways that value CES? Do the guidelines for promotion of faculty articulate CES across the faculty roles of research, teaching, and service? Advancing CES does not mean that all faculty will be involved in CES but that those who are doing CES or who aspire to do CES will be recognized and rewarded for their community-engaged teaching, research, and creative activities.

A review of practices at campuses nationally indicates that in order to expand and strengthen community-engaged scholarship, the work of faculty in this area must be documented, recognized, and rewarded (Ellison \& Eatman, 2008). Through interviews with 20 engaged scholars at U.S. research institutions, Moore and Ward (2010) found that when institutions expressed sincere support for CES but did not value it through promotion and tenure policies, traditional scholarship was privileged. To cope, engaged scholars have positioned their work as traditional scholarship or ensured that they have had enough traditional scholarship in addition to CES in order to secure tenure (Moore \& Ward, 2010).

When institutional policies are silent on engagement, they create disincentives for faculty to undertake community engagement across their faculty roles and often punish them when they do (O'Meara, 2016). Silence perpetuates what O'Meara (2016) identified as “inequality regimes" of power, privilege, and oppression in which traditional scholarship is privileged and faculty agency over their own professional pathways is severely limited. O'Meara argued that "we need interventions (institution wide and department focused) that disrupt or dismantle organizational practices that reinforce inequalities and help faculty navigate and craft meaningful careers in higher education organizations" (p.104). We would add the need for college-wide interventions. Institutions need to create what Sturm (2007) called an "architecture of inclusion," 
empowering community-engaged scholars to develop fully as professionals in the academy (O’Meara, 2016).

For example, UNC-Chapel Hill's Academic Plan 2011 set forth the strategic priority of building engaged scholarship into the core culture of the campus and throughout all academic units:

The recommendations of the Task Force on Future Promotion and Tenure Policies and Practices ... should be adopted.... [F] aculty engagement is defined as ... scholarly, creative or pedagogical activities for the public good, directed toward persons and groups outside the University of North Carolina at Chapel Hill. Such activities (in the form of research, teaching, and/or service) develop as collaborative interactions that respond to short and long-term societal needs.... The University should adopt an explicit policy stating that although engaged scholarship need not be a prerequisite for promotion and tenure, excellence in such scholarship will be acknowledged and rewarded. Each academic unit should review and revise its tenure and promotion criteria to include engaged scholarship and activities as appropriate for their discipline. (p. 23)

This language highlights the importance of aligning reward policies at the department, college/school, and institutional levels to build a culture of engagement.

Scholarship in Public emphasizes the concept of a continuum of scholarship as an organizing framework for revising promotion and tenure policies to support CES. When drafting policy language on CES, it is important to ensure that it cuts across the key areas of faculty work - teaching, research, and service - and recognizes a diverse body of possible evidence of impact (Ellison \& Eatman, 2008; Holland, 2009; O’Meara et al., 2011; Saltmarsh et al., 2009). Dana and Emihovich (2004) pointed out that

the educational research community has never seriously grappled with the concept of "impact" within the practitioner community as a measure of achievement comparable to the sheer volume of output in the form of articles, monographs, and books that few practitioners may ever read. (p. 44)

Across the United States, many campuses are at some stage of reconsidering and revising their reward structures to recognize new forms of scholarship and the scholars who are producing it. This is critical, especially as new young scholars, with training, goals, and values significantly different from traditional models, begin their careers in academic institutions. Further, there is an increasing number of scholars coming into the academy, often much more diverse in every way from the faculty currently on campus and who have significant interest in emerging forms of scholarship such as digital scholarship, interdisciplinary scholarship, and CES (Dana \& Emihovich, 2004; Ellison \& Eatman, 2008; O’Meara et al., 2011.)

Since colleges or schools within a university have their own disciplinary expertise as well as faculty peer-review systems as part of a promotion and tenure process, instituting policies at the college/school level in explicit support of CES is critical.

Capacity-building infrastructure for support and sustainability. Administrative centers for community engagement play a key role in facilitating and sustaining community engagement in higher education (Quaranto \& Stanley, 2016; Sandmann \& Plater, 2009; Strand, Cutforth, Stoecker, Marullo, \& Donohue, 2003). In their review of 56 successful Carnegie Community Engagement Classification applications, Sandmann and Plater (2009) identified 
three unique models for community-engagement centers: coordinating centralized centers, diffused networked units, and hybrid coordinated units. A capacity-building structure within a college/school could serve as a centralized coordinating structure for that college/school, and it might also be connected to a network of similar centers across campus or a larger centralized center for the entire university.

Community-engagement centers play a facilitative role by mobilizing resources, building and maintaining campus-community relationships, recruiting and managing participation of faculty and students, bringing relevant expertise and resources together around projects, creating criteria and processes for undertaking and implementing research projects, creating sustainability mechanisms, and ensuring that research is directed toward social-change goals (Sandmann \& Plater, 2009; Strand et al., 2003). The relationship building that goes into CES and maintaining campus-community partnerships is time-consuming, making the role of a staffed center critical to success.

Centers also facilitate essential professional development for CES scholars to increase awareness and understanding, create a community of scholars, and increase participation (Holland, 2009). O'Meara (2016) emphasized the importance of helping CES faculty "navigate and craft meaningful careers in higher education organizations" (p.104) that may privilege traditional scholarship. Centers play a role in this by providing professional development, building community, and allocating resources. Centers may also facilitate mentoring among community-engaged scholars, an important element of professional community building and sustained engagement (Ellison \& Eatman, 2008; Moore \& Ward, 2010).

Another aspect of infrastructure to support CES is personnel. A college/school can assess the appropriate level of fiscal support for designating a position or part of a position to facilitate CES. This may take the form of an administrative position or a faculty member with particular expertise who is released from other duties to mentor and guide this work.

No matter the form of infrastructure, it is important that the structural components of a college/school that promote CES (e.g., a center, dedicated personnel, etc.) be adequately funded. A serious systemic approach to CES involves adequate resources being designated to this effort. For example, central to capacity building is the disbursement of stipends or seed money for engaged research or course development (Aminzade, 2004). Availability of funding helps sustain projects and serves as evidence of recognition and legitimization of CES (Moore \& Ward, 2010). Additionally, it is important that funding be made available for faculty and graduate students to attend CES conferences because these are non-disciplinary conferences, and most faculty will use annual faculty development funds for their attendance at disciplinary conferences.

Assessment. Recognizing the multiple foundational components that build and sustain a culture of community engagement - from mission and vision to curricular pathways and faculty support, and mutually beneficial campus-community partnerships-Furco and Miller (2009) emphasized the importance of assessing and benchmarking each component to track and facilitate success. The development and implementation of assessments are strengthened at the college of school level since those units have their own governance structures and cultures.

Furco and Miller (2009) identified several categories of assessment focused on institutionalization that range in complexity and serve varied purposes. Self-assessments, indicators, and checklists are internally focused and help locate where a college/school may be in the institutionalization process, while benchmarks, rubrics, and matrices are more formal 
assessments that require empirical data and examine levels or stages of institutionalization. System approaches include a "battery of instruments, procedures and approaches to provide a more comprehensive assessment" (p. 50). Systems may focus on all foundational elements of institutionalization or a specific element such as service-learning or CES. Similarly, there are numerous tools for measuring community engagement practice and student-learning outcomes such as IUPUI's Civic-Minded Graduate Scale (see https://csl.iupui.edu/teaching-research/toolsinstruments/graduate/index.html).

As Furco and Miller (2009) highlighted, for any assessment approach to be effective, it is important to clearly define terms like community engagement or community-engaged scholarship. This may look different in different academic disciplines; therefore, clarity at the local level of a college/school is key. One cannot assess that which one cannot define. Similarly, it is important to understand the purposes of any assessment since that will inform the methods used, stakeholders involved, and timing.

Career pathways. Critical to the ongoing and long-term success of CES is the creation of a pipeline or pathway for faculty and student scholar-practitioners from graduate school into their careers (Aminzade, 2004; Ellison \& Eatman, 2008; Gillette, 2017, 2018; Moore \& Ward, 2010; O’Meara, 2016). David Scobey said, "We have to develop a picture of the successful trajectory of an academic career as a public scholar" (as cited in Ellison \& Eatman, 2008, p. 21). Because scholarly trajectories often center on discipline-specific activities and expertise, having clear pictures of such trajectories within a college/school can transform a culture and provide visible, accessible models for emerging scholars. Drawing from the engaged department model, Kecskes (2006) suggested that faculty and students alike should think about what and how their disciplines can contribute to the common good. For example, students in the sociology department at the University of Minnesota Twin Cities are encouraged to "think critically about the role of sociological knowledge in the contemporary world and to reflect on how the knowledge, skills, and insights of the sociological enterprise can be used and applied in their lives and careers outside of the university" (Aminzade, 2004, para. 4). Students also receive a community scholar designation on their transcripts. Similarly, Gillette (2018) discussed the importance of a college of education as a unit of community engagement that prepares teachers who are "justice oriented, urban 'insiders' who would teach in their home community, act from an ethic of care, and prioritize trust and relationship building with students, families, and community members" (p. 119).

Organizations like Imagining America and the International Association for Research on Service-Learning and Community Engagement promote academic pathways for graduate students by offering awards, scholarships for conference participation, and access to mentors and graduate student networks. The Imagining America Publicly Engaged Scholars Study (see https://imaginingamerica.org/initiatives/engaged-scholars-study) aims to "deepen our understanding about the career arc for publicly engaged scholarship and practice." Preliminary findings from the study point to seven profiles of engaged scholars: (1) the scholar motivated by personal values and involvement with their local community; (2) the local artist "who uses the community as a "canvas"'; (3) the K-12 teacher who enters the academy and takes on an active research role; (4) the community-engaged professional, which includes center directors within higher education; (5) the "interdisciplinarian" who pulls from many disciplines to enhance community-engaged work; (6) the activist who "uses the university as a platform to further pursue their activism"; and (7) the "engaged pragmatist," who sees CES as the direction in which 
higher education is moving and wants to be a step ahead. The purpose of creating these profiles is to help higher education leaders understand what motivates and draws community-engaged scholars to inform recruitment and program development.

Although the eight components of a college/school that can be instrumental in advancing CES are thoughtfully grounded in higher education literature and practice as well as in CES research, we do not intend to offer a comprehensive list here. Others may identify key components within their particular university setting. In addition, the components we have identified are not independent or mutually exclusive; they overlap in function and in practice. However, we believe that these eight areas are highly impactful for guiding college/school leaders in assessing their own level of engaged scholarship and for identifying pathways for advancing CES.

\section{The Design of the Rubric}

To assist colleges or schools within universities in advancing community-engaged scholarship, we developed an assessment and planning rubric that aligns with the components of a college/school as described earlier. The rubric's purpose is to serve as a tool for self-reflection and planning as academic units try to enact practices in support of CES, encouraging them to consider their own local context, the strengths and values of their faculty, and their resources.

For the purpose of the rubric design, we used the definition of community-engaged scholarship outlined earlier in this article. Scholarship is community-engaged when it involves reciprocal partnerships and addresses public purposes. The rubric defines community-engaged scholarship in this way:

Community engagement in the context of this rubric refers to relationships between those in the college and those outside the college that are grounded in the qualities of reciprocity, mutual respect, shared authority, and co-creation of goals and outcomes. Such relationships are by their very nature transdisciplinary (knowledge transcending the disciplines and the college) and asset-based (valid and legitimate knowledge exists outside the college). Transdisciplinary and asset-based frameworks and approaches impact both pedagogy and scholarship. They also inform an organizational logic such that colleges will need to change their policies, practices, structures, and culture in order to enact engagement and support scholars involved in community-engaged teaching and learning and community-engaged knowledge generation.... [S]cholarship is communityengaged when it involves reciprocal partnerships and addresses public purposes. Community-engaged scholarship is characterized by creative intellectual work based on a high level of professional expertise, the significance of which can be validated by peers, and which enhances the fulfillment of the mission of the campus/college/department. Community-engaged scholarship meets the standards of research when it involves inquiry, advances knowledge, is disseminated, and is open to review and critique by relevant academic, community, or professional peers. Community-engaged research conceptualizes "community groups" as all those outside of academe and requires shared authority at all stages of the research process, from defining the research problem, choosing theoretical and methodological approaches, conducting the research, developing the final product(s), to participating in peer evaluation. Research is community-engaged when faculty, students, community-based organizations, government agencies, policy makers, and/or other actors collaborate to identify areas of inquiry, design studies and/or 
creative activities, implement activities that contribute to shared learning and capacity building, disseminate findings and make recommendations or develop initiatives for change.

A number of the rubric components were adapted from O’Meara (2016) and draw significantly on research from the widely known rubric developed by Furco (2002). While Furco's rubric is grounded in research on institutionalizing service-learning, we revised and extended it to be relevant to all aspects of CES in research, teaching, and service.

The self-assessment rubric contains eight dimensions based on the literature described earlier, each of which includes a set of components representing aspects of the operationalization of the dimension. Ewell (1998) has written that in order to achieve transformative organizational change, it is necessary to work on multiple components of an institution simultaneously.

To achieve the institutionalization of community engagement into the culture of a college, there is no single intervention that will create an organizational environment where engaged scholars will thrive. Multiple actions in multiple areas need to be attended to at the same time. The rubric is designed based on a consideration of the literature and current practice. The eight rubric dimensions identify broader strategic areas, and the components within each dimension indicate activities that aimed at operationalizing the dimensions (see Table 1). 
INSTITUTIONALIZING COMMUNITY ENGAGEMENT

Table 1

College-Level Self-Assessment Rubric Dimensions and Components

DIMENSION COMPONENTS

I. Leadership and Direction
- Hiring criteria for dean and chairs

- Leadership development opportunities for dean and chairs

- Faculty council that meets regularly and advises college decision making on engagement and resources

- Advisory Leadership Council that includes community partners, faculty, staff, and students

\section{Mission and Vision}

- Articulation in mission and vision statements

- Definition of community-engaged scholarship

- Strategic planning

- Alignment with institutional mission

- Alignment with educational innovations

- Alignment with accreditation

- Alignment with complimentary strategic priorities (i.e., diversity, inclusion and equity; student success; engaged learning through high-impact practices)

- Funding priority
III. Visibility Communication and

- Positioning engaged scholarship on the web, via YouTube clips, in college and department publications, and reports to executive administration

- (faculty) Hiring - job descriptions that emphasize CES

- (students) Recruitment and admissions criteria that are explicit about valuing community engagement

- Membership and participation by dean, chairs, faculty, staff, and students in networks focused on advancing community engagement

\section{Recognition}

- College awards for CES

- Engaged department award

- Annual faculty activity report - data collected on CES

- Annual faculty activity reports that allow faculty to get credit for mentoring for CES

- A place for CES in official college CV form

- Merit pay criteria that recognizes CES 


\section{DIMENSION}

\section{Rewards}

\section{COMPONENTS}

- CES is valued in promotion and tenure via definitions of scholarship, criteria, documentation, peer review

- Community engagement included in evaluation criteria for term contracts for NTT faculty

- Sabbaticals - CES encouraged for sabbaticals

- Post-tenure review-CES and teaching and learning valued in post-tenure review criteria

\begin{tabular}{|c|c|c|}
\hline VI. & $\begin{array}{l}\text { Capacity-Building } \\
\text { Infrastructure for Support } \\
\text { and Sustainability }\end{array}$ & $\begin{array}{l}\text { - Administrative assistance-staffing to support } \\
\text { - } \text { Demmunity engagement } \\
\text { - Assistance developing partnerships, memoranda of } \\
\text { understanding with community partners } \\
\text { - Faculty development programs for integrating } \\
\text { community engagement into scholarship and teaching } \\
\text { - Training for personnel review committee members on } \\
\text { evaluating CES } \\
\text { - Formal and informal mentoring programs } \\
\text { - Stipends or course release for seeding engaged research } \\
\text { or course development } \\
\text { - Structured opportunities for faculty to connect with } \\
\text { community partners } \\
\text { - Writing retreats and assistance finding places to submit } \\
\text { CES for publication } \\
\text { - Assistance with grant writing to support community } \\
\text { engagement } \\
\text { - Conference support for faculty and graduate assistants } \\
\text { (in addition to faculty development resources for } \\
\text { disciplinary conferences) } \\
\text { - Interfacing with other engagement units on campus }\end{array}$ \\
\hline VII. & Assessment & $\begin{array}{l}\text { - Data collected and assessed on faculty engaged } \\
\text { scholarship } \\
\text { - Data collected and assessed on community-engaged } \\
\text { courses } \\
\text { - Data collected and assessed on community engagement } \\
\text { learning outcomes } \\
\text { - Data gathered and assessed on community perceptions of } \\
\text { partnerships } \\
\text { - Measures established and data gathered and assessed on } \\
\text { community impacts } \\
\text { - Interfacing with Institutional Research to draw on } \\
\text { campus data that will assist with assessment of } \\
\text { community engagement (e.g., NSSE results, HERI } \\
\text { faculty survey) }\end{array}$ \\
\hline
\end{tabular}




\section{DIMENSION}

VIII. Curricular Pathways

\section{COMPONENTS}

- Community engagement in the curriculum of majors and graduate programs

- Community engagement in college minor

- Community engagement graduate certificate

- Completion of a community engagement minor or graduate certificate appears on the official transcript.

\section{Dimensions of the Rubric}

\section{Leadership and Direction}

The literature on community engagement emphasizes the importance of leadership in supporting community engagement. At the level of the college, this means that leadership by the dean (and associate deans) and department chairs is critical. This can be achieved more quickly and reach greater depth and pervasiveness if the individuals who are hired into these positions of leadership have some background in community engagement, and that the job descriptions for hiring the dean and chairs include criteria around community engagement. Regardless of previous experience, it is be important for dean and chairs to have leadership development opportunities so that they remain current on developments in the field, on best practices, and on how to exercise leadership from the top that builds leadership from the bottom in the college. The administrative leadership in the college can be fostered by the faculty governing body, which may establish a standing committee to provide guidance for the college on advancing community engagement. The administrative leadership of the college is also in a position to model collaboration by establishing an advisory council for the college that includes among its members the deans, a representative of the chairs, faculty, staff, community partners, and students. By intentionally building community engagement into the role of leadership in the college, community engagement will not be person-dependent and will have a greater likelihood of being deepened and sustained.

\section{Mission and Vision}

In order for community engagement to be central to the culture of the college, it must be clearly articulated in the unit's mission and vision. In mission-driven institutions, it is difficult to advance any activity that is not clearly aligned with that mission. Further, if those in the college do not see community engagement as serving their own self-interest - in advancing the mission, improving teaching and learning, or doing more meaningful and impactful research - then it will be difficult to view community engagement as more than a peripheral activity. It is also important, more on an operational level, to develop a clear and conceptually concise definition of community engagement to convey what is, and what is not, considered community-engaged scholarly work. With a clear mission and definition in place, the goal then is to align the work of community engagement in the college with the larger institutional mission, with accreditation standards (e.g., demonstrating contributions to the public good), with other institutional innovations (e.g., improving teaching and learning), and with other institutional priorities (e.g., increasing student and faculty diversity, or increasing student persistence and graduation rates). 
If community engagement is positioned at the core of the work of the college, then college and institutional fundraising for the college will be explicit about seeking grants and donors that will support the work.

\section{Visibility and Communication}

When community engagement is part of the identity of the college, it is made visible both internally on campus and to external stakeholders. It is positioned in a way that tells the story of the college, in data and reports and in narratives about the work of students and faculty. It is part of the way the college expresses its values and indicates the knowledge and skills that are valued by the college when recruiting faculty. It is also part of the way the college markets itself to parents, guardians, and students, indicating what can be expected in the educational experience for students. As a way to strive toward greater excellence in community engagement, the leadership in the college shares its work with others and learns from others through national and international networks focused on community engagement in higher education.

\section{Recognition}

Recognition and rewards are concrete expressions of the value of community engagement in the college. Recognition is more structural and typically easier to implement. Rewards are associated with cultural change and present greater obstacles for implementation. Recognition centers on awards and the prestige and visibility that come with them. Colleges can encourage community engagement by including it as part of annual faculty reporting and by encouraging mentoring as an activity valued by the college. Tying merit pay to community engagement also signals the importance of community engagement as faculty work valued by the college. Recognition is not a substitute for rewards but can serve as an important complement to them.

\section{Rewards}

The policies and criteria that constitute the basis for faculty review and promotion are artifacts of the core academic culture of the college. The guidelines for faculty review express a common set of beliefs and values, as well as underlying assumptions, epistemic orientations, and interpretive frameworks. Often, guidelines are not explicit, allowing the culture to operate outside of codifying expectations. Yet, when there are not explicit incentives for faculty to do community engagement as part of their faculty roles, then there are disincentives. Further, when the culture of faculty work positions community engagement as work that is understood as only being included in the faculty's service role, it is not tied to faculty work generating knowledge or in teaching and learning. Reward structures that explicitly articulate community-engaged scholarship across the faculty roles create a process of fairness for faculty who identify as community-engaged scholars. The goal is to establish guidelines and a culture that recognize CES and allow community-engaged scholars to thrive and excel (not to merely survive and delay their work until after promotion). Making CES explicit in rewards policies for tenure-track and non-tenure-track faculty is a matter of fairness, not an attempt to devalue the work of scholars who do not employ collaborative and participatory epistemological approaches to research, creative activity, and teaching and learning.

\section{Capacity-Building Infrastructure for Support and Sustainability}

While more and more faculty coming out of graduate school and into the professoriate have had some experience with community engagement and are more experienced with collaborative knowledge generation, many faculty have not been exposed to community 
engagement as part of their professional preparation or socialization in their discipline. In order to operationalize community engagement, faculty need to develop the capacity to integrate it into their core academic work. The more opportunities there are for faculty to participate in faculty development that is oriented toward their discipline, the more beneficial that professional development will be. While the campus as a whole may have a coordinating infrastructure that offers faculty development for community engagement, the college should explore whether that infrastructure is adequately meeting its needs. The closer community engagement capacity building is to the culture of the college, in areas like mentoring, training for personnel review committees on evaluating community-engaged scholarship, and grant seeking and writing support, the more these activities should be implemented in the college.

\section{Assessment}

Colleges measure what they care about. If the college values community engagement, and if it models best practices of community engagement, then there will be multiple mechanisms for systematically assessing its results and outcomes. Assessment can reveal how deep and pervasive community engagement is in the college. It can demonstrate how it impacts student learning. It can help determine how community partners perceive the engagement of the college and attempt to understand what difference the college's engagement makes in the communities with which it interfaces. Assessment is an essential means of understanding impact and improving practice.

\section{Curricular Pathways}

A central way that community engagement impacts the academic experience of students is through its incorporation into the curriculum. When community engagement is part of the college's identity and culture, there should be opportunities for every student to include community engagement as part of courses in their undergraduate major or graduate program. There should also be opportunities for undergraduates to complete a minor in community engagement as a way of doing more in-depth community engagement during their academic study. Similarly, graduate students across the college should be able to earn a graduate certificate in community engagement in order to deepen their knowledge and skills as engaged scholars and to enhance employment opportunities post-graduation. In all cases, there should be clear pathways through the curriculum for students at any level to pursue and deepen their community engagement through their coursework.

Finally, each dimension of college engagement intersects with, reinforces, and enhances the other. The rubric is designed to allow colleges to assess the cultures, structures, policies, and practices that can be implemented to advance community engagement as a core academic identity. College-level engagement complements individual faculty engagement, departmental engagement, and institutional engagement - and when done well can enhance all of these. As an inventory of engagement in the college, the rubric makes visible an architecture for community engagement and provides a blueprint for guiding the college in building, deepening, and sustaining community engagement.

\section{Stages of Progress}

Within each dimension of the rubric, for each component, a college working group at each of the four pilot universities determined the stage of progress that best represented the college's level of engagement based on the evidence examined. The rubric provides three stages 
of progress: Emerging, Developing, and Transforming, with space left for identifying evidence for their assessment. The stages of the rubric are described as follows:

- Stage 1: Emerging. At this stage, a college is beginning to recognize community engagement as a strategic priority and is building a college-wide constituency for the effort.

- Stage 2: Developing. At this stage, a college is focused on ensuring the development of its institutional capacity and the capacity of individuals to sustain the community engagement effort.

- Stage 3: Transforming. At this stage a college has fully institutionalized community engagement, and it has mechanisms in place to ensure progress and sustainability, continuing to assess its progress and achievements as it looks toward the future.

- Indicators. Evidence of change in policy, practices, structures, and culture.

For example, for the Leadership dimension and the component of "hiring criteria for deans, associate deans, and department chairs," the working groups were instructed to identify the stage of development based on the evidence examined:

\section{DIMENSION I: Leadership and Direction}

A primary feature of institutionalized community engagement in a college is long-term, sustained, consistent, and committed leadership at the administrative level, among the dean, associate deans, and department chairs.

DIRECTIONS: For each of the components (rows), place a circle around the cell that best represents the CURRENT status of the development of intentional identification and development of leadership for community engagement. Once the current status of development has been established, then identify evidence of this status in the corresponding INDICATORS cell.

\begin{tabular}{l|l|l|l|l}
\hline COMPONENT & $\begin{array}{l}\text { STAGE 1 } \\
\text { Emerging }\end{array}$ & $\begin{array}{l}\text { STAGE 2 } \\
\text { Developing }\end{array}$ & $\begin{array}{l}\text { STAGE 3 } \\
\text { Transforming }\end{array}$ & INDICATORS \\
\hline $\begin{array}{l}\text { 1. Hiring criteria } \\
\text { for dean, associate } \\
\text { deans, and } \\
\text { department chairs }\end{array}$ & $\begin{array}{l}\text { There are no } \\
\text { criteria around } \\
\text { community } \\
\text { engagement in the } \\
\text { qualifications for } \\
\text { hiring of the dean, } \\
\text { associate deans, } \\
\text { and chairs. }\end{array}$ & $\begin{array}{l}\text { There } \\
\text { community } \\
\text { engagement } \\
\text { criteria in the } \\
\text { qualifications for } \\
\text { the hiring of the } \\
\text { dean and chairs, } \\
\text { but they are criteria for } \\
\text { largely rhetorical } \\
\text { community } \\
\text { engagement as a } \\
\text { and alification for } \\
\text { hiring of the dean } \\
\text { and chairs and } \\
\text { inconsistently. }\end{array}$ & $\begin{array}{l}\text { andioritized and } \\
\text { applied are } \\
\text { consistently. }\end{array}$ & \\
\hline
\end{tabular}




\section{Piloting the Rubric}

The goal of this project and the pilot was to contribute to the literature on community engagement and the advancement of community-engaged scholarship by focusing on the college as the unit of engagement. We did this by attending to the organizational elements of colleges that foster a culture of engagement, and by developing an instrument for colleges to assess the structures, policies, and practices they have in place for advancing CES.

\section{Methodology}

The colleges within the four research universities chosen for the pilot could be in any academic area. Criteria for selection into the pilot were as follows:

- the campus was classified by the Carnegie Foundation as Community Engaged (indicating a third-party verification of institution-wide commitment to community engagement); and,

- the researchers had access to a campus informant, someone in a position to identify possible college units that could participate in the pilot study. There is no national dataset or record that indicates which colleges in a university are incorporating community engagement into their academic activities. Therefore, we needed a trusted informant who could assist in identifying potential colleges and establish contacts with those colleges.

Based on these criteria, four colleges were chosen for the study:

- College of Arts and Humanities at Weber State University

- College of Arts and Sciences at Rutgers University, Newark

- College of Arts and Sciences at Drexel University

- School of Health and Human Sciences at University of North Carolina at Greensboro

Colleges were invited with the expectation that they would participate in an initial virtual meeting and one virtual cohort meeting part way into the pilot. Each colleges in the pilot was asked to form a working group that would implement the assessment process. The invitation to the colleges stated that

we are asking for your participation only if it makes sense for advancing community engagement on your campus. We are not in a position to offer any financial resources to the participating colleges, so there has to be an inherent self-interest on the part of the participating colleges that this will assist them in advancing community engagement as one of their goals. What we want to learn is the effectiveness of the self-assessment rubric, how we can improve it, and what process work best in implementing it.

From January through April 2017, the colleges implemented their self-assessments using the rubric. Between April and June 2017, researchers visited each of the campuses to meet with those responsible for rubric implementation within the college. Finally, each college was asked to submit a final report and was provided a template for structured data gathering that included the following questions:

1. Who was involved in planning/decision making on implementation of the rubric? How were those participants chosen? What was their role? 
2. What were the roles of college and university leadership (i.e., dean, associate deans, and chairs) in decision making and implementation of the project?

3. What organizational structures (e.g., committees, leadership, governance groups, etc.) were consulted during the process? How were they involved?

4. How was the rubric introduced to the college community? What expectations were established for participation in its implementation?

5. How was implementation of the rubric structured? Who played a role? What current structures or activities in the college were used? What accountability or feedback was established?

6. What was the impact of the implementation process?

7. What were some outcomes from the process?

During June 2017, we held one last virtual meeting with the entire cohort. Our aim with the pilot campuses was to gather information about the rubric and the implementation process. The goal of the pilot was to refine the rubric for dissemination to the field.

\section{The College Working Group}

At two of the four colleges in the pilot, an associate dean took the lead in organizing the effort. At another college, the process was organized by a senior assistant dean, and at the other college, the process was initiated by the dean and organized by the community-engagement center director who was also a faculty member in the college. One college had faculty representatives on their team from each department in the college. At another college, a total of 12 faculty participated in two meetings that were held, but not the same faculty at both meetings. One college team included six faculty members from various disciplines and the director of the campus center for community engagement. At the other college, the working group included two faculty members, two associate deans, and the community-engagement center director, who also held faculty rank in the college.

Each working group approached the process somewhat differently, but the common pattern was to have an initial meeting, determine the data needed to address the areas in the rubric, divide the work into smaller teams, and come back with as an assessment. A final meeting was held to formulate recommendations based on the findings. For example, one college working group describe their process in this way:

The committee was initially introduced to the rubric and determined the utility of the process and rubric tool. All faculty members were in agreement that the tool has potential for a formative and substantive evaluation. The first committee meeting was scheduled for a three hour block which allowed the members to identify the data needed, determine the indicators and develop a plan to delegate the review. Two members were assigned to each dimension and independently coded the data. A final three hour working meeting reviewed each dimension and criteria. The reviewers discussed their assessment and the members asked clarifying questions or contributed to the final assessment. Additionally, the committee as a group made rubric-and [college]-specific recommendations.

\section{Findings}

Implementing the rubric revealed ways in which institutional community engagement infrastructure could be better connected to college community engagement activity and faculty. There was a tendency for faculty who identified as community-engaged scholars to build 
relationships with the campus community-engagement center, often participating in its activities and making use of its resources, but not connecting that work back to their college. In more than one case, this led to a recommendation that the college formalize the designation of a college liaison to the center.

Use of the rubric also revealed ways in which the college as a unit could better support faculty engagement in alignment with institutional efforts. For example, strategic efforts at the institutional level to revise faculty rewards so as to better recognize and value community engagement as legitimate scholarly work were often not reinforced or translated into college documents and processes.

In most of the colleges, deans discovered a new role, moving from being supportive to actively working with faculty to advance community engagement. Deans reported gaining a deeper understanding of the kinds of resources and supports faculty need to pursue community engagement in their research and teaching. Deans who had relied on the institutional infrastructure of the community-engagement center to advance the work of community engagement now understood the importance of a complementary role for the college to advance that agenda.

Working groups reported that the rubric revealed significant unevenness across departments in a college. This provided an opportunity for reflection on the implications of uneven quality and depth of community engagement for student learning, for junior faculty trying to read the cultural tea leaves in the college as they prepared for promotion and review, for attracting students to the college, and for faculty and staff hiring. This kind of reflective process led two of the colleges to envision explicitly a role for the college as a model for community engagement, assisting other colleges on the campus to conduct their own assessment process.

Three of the four colleges were situated in an institutional environment with a robust infrastructure for community engagement. In all of those colleges, there were a number of areas indicating that the activities of the community-engagement center were better situated in the center and not in the college. For example, it was seen as duplicative for the college to establish an advisory council of administrators, faculty, staff, community partners, and students; this was best done through the center. Additionally, for faculty development activity conducted by the center, it was best that that activity was offered through the center, but the college could do a better job of partnering with the center to help build greater faculty capacity for community engagement for college faculty. The more an issue was seen as a college issue, the greater the perceived role of the college. For example, one campus noted that "training for personnel review committee members on evaluating community engaged scholarship" was a primary issue for the college that could be done in collaboration with institution-wide training opportunities.

Two of the working groups reported that the assessment process revealed the importance of faculty mentoring within the college. Mentoring of junior faculty was an activity best done within the college and was a way of making visible and recognizing the expertise of the more senior faculty doing community engagement while at the same time providing significant and meaningful additional support for junior faculty. It was a way to reinforce and build a deeper culture of engagement in the college. As an example, one campus recommended that the college "formalize mentor roles" in order "to help mentor new faculty and to develop ourselves and leaders/experts within our respective disciplines/fields." 
It should be noted that after going through the process of using the rubric to gather data about community engagement in the college, and using that data as of evidence for institutionalization of community engagement in the college, all of the colleges determined that they were in the early stages of the rubric, mostly in Stage 1, Emerging. This in itself, for most of the colleges, represented an awakening among the working group members and the deans for a renewed commitment to community engagement and targeted, strategic efforts to advance engagement in the college.

\section{Readiness}

The campuses in the pilot were selected because of indications that they were already doing substantive community-engagement work. It became clear that indicators of campus-wide engagement may not filter down to college-level engagement, and it raised the question about readiness to undertake the rubric assessment. We saw "readiness" as being different from a critical assessment of whether the rubric could be a useful tool for advancing college engagement. Early in the process, colleges raised critical reflective questions related to the context of operating in the shadow of a flagship institution and what that meant in terms of "performance anxiety" and "fear of erosion of scholarly standards" as they approached the rubric. On another campus, there was initial resistance from faculty - often the faculty who were the most engaged - because of questions about how the results of the assessment were going to be used. More than one college raised questions about the relationship of this project to other structures of engagement within and outside the college. All of these were crucially selfreflective questions that the colleges used to clarify their commitment to participating in the pilot.

The issue of readiness emerged early in the recruitment process as we reached out to colleges identified by local informants as potential participants in the pilot. At one college, the dean was concerned about the amount of time the process would take, the personnel hours, and competing priorities for those personnel (e.g., accreditation processes going on that same academic year). Had the college been at a different level of readiness, the evidence gathered for accreditation might have had greater overlap with evidence gathered for engagement, and the process might not have seemed so onerous or might have been seen as mutually reinforcing. On another campus, there was a concern early on that proceeding with the rubric would exacerbate some underlying tensions that had emerged in the college related to a perception that community engagement was being driven from the top administration of the university and had not reached the faculty in a way they were embracing. There was a conversation on campus among faculty that framed the community engagement work as a zero-sum equation: If community engagement was being valued, then what I do is not going to be valued. The same college faculty thought that the dimension of faculty rewards was a problem and that they did not want to address this; doing so was moving too fast for them.

Questions of readiness also emerged for us when a college would challenge the definition we used for community engagement, indicating a lack of conceptual clarity around the term. For example, one college shared input from faculty that scientists who receive NSF grants have a "broader impact" statement, but though the researchers have to include engagement with the community in this statement, the type of engagement they propose would not fit the definition used in the rubric. This is largely correct, in that NSF's interpretation of broader impacts focuses heavily on the dissemination of scientific knowledge to the public, not the involvement of the public in the generation of scientific knowledge. Not all public scholarship is publicly engaged 
scholarship, and the rubric is aimed at community engagement, not the sharing of academic knowledge with the public per se. As another example, at one college, the faculty recognized that community engagement was inconsistent and disjointed across the college, with some departments being deeply engaged. This led to the view that the engaged department might be the more appropriate level to assess. From our perspective, engaged-department work can be an important initiative leading to deeper institutionalization of community engagement, and there are rubrics that exist for assessing such work (Kecskes, n.d.). However, the rubric was designed specifically for the college as a unit, not the department. Not all colleges, regardless of the engagement profile of the entire campus, may be ready to undertake college-level engagement.

\section{Recommendations on Revising the Rubric}

For all of the colleges that participates in the pilot, there were parts of the rubric that seemed to resonate more strongly with the development of community engagement in the college than others. Overall, the colleges found that the dimensions of the rubric established a broad organizational perspective on community engagement that proved useful for thinking strategically about engagement. Again, depending on unique aspects of each college, there seemed to be dimensions that were missing. For example, one college recommended that a "cocurricular criterion be added" because the college had "several examples of co-curricular, discipline specific, opportunities" for community engagement.

There was a general perception that assessment can be controversial. Depending on the institutional culture, assessment can be viewed as something imposed by administration on the faculty to be used for punitive purposes. This can lead to resistance to assessment, and there were hints of that resistance in more than one college in the pilot. It was recommended by the cohort of colleges that shifting the terminology away from an "assessment rubric" to an "inventory" would help alleviate some of the anxiety associated with taking on such a substantive assessment effort.

It was also recommended that a more nuanced scale be developed-for example, creating a 5-point scale across the three stages of Emerging, Developing, and Transforming. The working groups thought that a more nuanced scale would better capture some of the important community engagement work in the college and refine planning efforts to advance community engagement.

It was also suggested that some components of the rubric be assessed as "not applicable." While the component may be an important consideration for college engagement, colleges noted that it is important to recognize that some activities are and should be done by the institutional coordinating infrastructure for engagement, and that duplication of activities is not an efficient or effective strategy.

Further, colleges noted that partnerships with the community are absent from the rubric and should be incorporated to enact authentic reciprocity in the assessment process. As with all partnership work, community partners need to be brought in at the design stage. This was an oversight on our part as we put together the rubric. If community partners were putting together a rubric for institutionalizing community-engaged scholarship in a college, what components would they consider essential?

Finally, participating colleges noted that an assessment of developmental activities was missing from the rubric, such as "courses being developed," "discussions that were occurring," and "intentions that were being set." Even though they had not been implemented, there were 
activities going on that evidenced a trajectory toward deeper engagement. Many believed that the rubric did not capture the space between the stages of Emerging and Developing, and they believed that important activities occurred in that space. As one college participant noted, "First steps or baby steps need to be captured." In other words, the rubric needs more nuance.

\section{Discussion}

As societal problems become more complex, many universities have focused on community-engaged scholarship as a way to use intellectual and scholarly capacity to address those concerns. Centers for community engagement have become more common in universities, and, in some places, faculty have been encouraged to shift their scholarly work to focus on concerns within their community. Strengths of university-wide CES initiatives include the transdisciplinary nature of community problems and solutions and the considerable human capital and resources that a university can bring to the table. However, as large complex organizations, universities often struggle with campus-wide initiatives and have variable participation across academic units. With their own mission and vision, access to disciplinebased community partners, and an adaptability that may elude a larger organization, colleges or schools within a university may be a powerful place to advance the work of CES. This study sought to support colleges or schools within universities to advance CES within their academic units through the use of an assessment and planning rubric.

Strong support and vision for CES has emerged from national groups such as the Carnegie Foundation and Imagining America. Many campuses have taken up this challenge and have included CES as part of their strategic plan and campus infrastructure. The colleges included in our study are parts of campuses where CES is accepted and encouraged. However, the pathway to coordinated, successful implementation of CES is often unclear. Academic leaders, both faculty and administrators, can use structured guidance on practices that support CES. The working groups from the four campuses involved in this study expressed the need for assistance with identifying next steps in their developing support for CES. All four colleges formed study teams to use the rubric to advance a structured conversation about the status of their CES and to identify next steps.

Although all four colleges were on supportive campuses with identifiable institutional supports, the teams confirmed a need for expertise and guidance around their reflection and planning. The presence of existing support and a readiness to engage with the work of CES seem to be important precursors to successful use of the assessment and planning rubric. It seems that reflection and planning at the college/school level may depend on prior work and commitment to the initiative. In this case, colleges or schools that have debated and embraced CES, provided some infrastructure, including knowledgeable colleagues, and have taken prior action, seemed capable of reflecting on the current status of CES. Purposefully, we did not include colleges that were in the beginning stages of embracing CES. The usefulness of an assessment and planning tool to an academic unit still debating whether to advance CES, struggling to define CES for themselves, and having little existing infrastructure to support CES may be limited. Future work with colleges at the beginning stages of CES will provide insight into the type of support these academic units need as they take up the work of CES.

The campuses that did participate found the rubric useful in planning their next steps for CES. To underscore the importance of reflection on this process, each of the campus teams that participated expressed surprise with areas in which they were still at the beginning stages of CES 
implementation, despite strong existing support and activity. The reflection process allowed them to build greater capacity through strengthening relationships based on common purpose and through underscoring the need for mentorship for faculty who are committed to CES but for whom CES was not a part of their academic training. Overall, this study confirmed the need for a reflection tool within academic units as a way to refine and focus practices in support of a common goal.

Our study also indicates the importance of developing models for shared leadership within academic institutions to advance priorities. Several of the deans of participating campuses indicated their support for CES but also their reliance on existing institutional infrastructure for advancing this work. Campus teams representing various departments and faculty or administrative roles were in a strong position to make recommendations for advancing CES. The deans played a leadership role in making this work possible through their support; however, the need for engaging others as leaders with critical expertise and perspectives was clear in the work on the four campuses.

An important impetus for our study was the unevenness of participation in CES across campuses that have been held up as models for CES. Our goal was to create a reflection and planning tool for academic units within universities to advance their CES within their disciplines. An unexpected finding was that the unevenness in participation also exists across departments within colleges or schools. It is unclear whether the process we asked the campus groups to engage in will address this unevenness or whether diverse levels of implementation are a part of any initiative since universities and their colleges or schools are large complex organizations.

As a result of our work on four campuses and further refinement of the reflection and planning rubric, we encourage more colleges/schools to engage in self-assessment and purposeful planning, even when their campuses are considered highly engaged. Further research could be conducted examining the use of the rubric across multiple colleges at a single university. In fact, one of the colleges participating in the pilot study did so with the intent of becoming a model for the other colleges at the university so as to eventually have all colleges become deeply engaged. Further research could also examine the implications of creating communities of practice made up of colleges implementing the rubric both within a single university and across universities. Additionally, our pilot study raises interesting questions about infrastructure for community engagement that could be explored further: How should an institution-wide coordinating infrastructure interface with colleges to advance communityengaged scholarship, and to what extent, given their core academic focus, should colleges establish internal infrastructure to support CES?

In order to encourage use of the rubric for both practice and for research, the rubric is made publicly available for use by colleges within a university in this issue of the eJournal of Public Affairs. We recommend campuses use the findings from the study to adapt the rubric to their own organizational context. 


\section{References}

Aminzade, R. (2004). The engaged department: Public sociology in the Twin Cities. Footnotes: Newsletter of the American Sociological Association, 32(8), 50-51.

Battistoni, R. M. (Ed.). (2003). The engaged department toolkit. Boston, MA: Campus Compact.

Brown University. (n.d.). Carnegie Classification. Retrieved from https://www.brown.edu/swearer/carnegie

Dana, N. F., \& Emihovich, C. (2004) Actualizing a culture of engaged scholarship in the College of Education at the University of Florida. Journal of Higher Education Outreach and Engagement, 10(1), 29-46.

Doberneck, D. M., Glass, C. R., \& Schweitzer, J. (2010). From rhetoric to reality: A typology of publically engaged scholarship. Journal of Higher Education Outreach and Engagement, 14(4), 5-35.

Ellison, J., \& Eatman, T. K. (2008). Scholarship in public: Knowledge creation and tenure policy in the engaged university. Retrieved from http://imaginingamerica.org/wpcontent/uploads/2015/09/TTI_FINAL.pdf

Ewell, P. (1998). Achieving high performance: The policy dimension. In W. G. Tierney (Ed.), The responsive university: restructuring for high performance. Baltimore, MD: Johns Hopkins University Press.

Furco, A. (2002). Institutionalizing service- learning in higher education. Journal of Public Affairs, 6, 39-67.

Furco, A., \& Miller, W. (2009). Issues in benchmarking and assessing institutional engagement. New Directions for Higher Education, 2009(147), 47-54.

Gillette, M. D. (2017). Sustaining a quality education through community-based educator preparation. Kappa Delta Pi Record, 53(4), 148-151.

Gillette, M. D. (2018). Walking into the community: Community partnerships as a catalyst for institutional change in higher education. In M. R. Warren \& D. Goodman (Ed.), Lift us up, don't push us out!: Voices from the front lines of the educational justice movement. Boston, MA: Beacon Press.

Holland, B. A. (2009). Will it last? Evidence of institutionalization at Carnegie classified community engagement institutions. New Directions for Higher Education, 2009(147), $85-98$.

Imagining America. Engaged Scholars Study. Retrieved from http://imaginingamerica.org/ initiatives/engaged-scholars-study/

Hyman, D., Gurgevich, E., Alter, T., Ayers, J., Cash, E., Fahnline, D., ... \& Swisher, J. (2002). Beyond Boyer: The UniSCOPE model of scholarship for the $21^{\text {st }}$ century. Journal of Higher Education Outreach and Engagement, 7(1\&2), 41-65.

Kecskes. K. (n.d.) Creating community-engaged departments: Self-assessment rubric for the institutionalization of community engagement in academic departments. Retrieved from https://www.pdx.edu/sites/www.pdx.edu.cae/files/Engaged\%20Department\%20RUBRIC \%20-\%20Kecskes\%202009-paginated.pdf 
Kecskes, K. (2006). Engaging departments: Moving faculty culture from private to public, individual to collective focus for the common good (Vol. 72). San Francisco, CA: JosseyBass.

Moore, T. L., \& Ward, K. (2010). Institutionalizing faculty engagement through research, teaching, and service at research universities. Michigan Journal of Community Service Learning, 17(1), 44-58.

O’Meara, K. (2016). Legitimacy, agency, and inequality. In M. Post, E. Ward, N. Longo, \& J. Saltmarsh (Eds.), Publicly engaged scholars (pp. 96-110). Sterling, VA: Stylus.

O’Meara, K., Eatman, T., \& Petersen, S. (2015). Advancing engaged scholarship in promotion and tenure: A roadmap and call for reform. Liberal Education, 101(3), 52-57.

O’Meara, K., Sandmann, L. R., Saltmarsh, J., \& Giles, D. E. (2011). Studying the professional lives and work of faculty involved in community engagement. Innovative Higher Education, 36(2), 83-96.

Quaranto, J., \& Stanley, D. (2016). Community-based research from the perspective of the community partners. In M. Beckman \& J. Long (Eds.), Community-based research: Teaching for community impact (pp. 50-68). Sterling, VA: Stylus.

Saltmarsh, J., \& Gelmon, S. (2006). Characteristics of an engaged department: Design and assessment. In K. Kecskes (Ed.), Engaging departments: Moving faculty culture from private to public, individual to collective focus for the common good (pp.27-44). Bolton, MA: Anker Publishing.

Saltmarsh, J., Giles, D. E., Jr., O'Meara, K., Sandmann, L., Ward, E., \& Buglione, S. M. (2009). Community engagement and institutional culture in higher education: An investigation of faculty reward policies at engaged campuses. In B. E. Moely, S. H. Billig, \& B. A. Holland (Eds.), Advances in service-learning research: Creating our identities in servicelearning and community engagement (pp. 3-29). Charlotte, NC: Information Age Publishing.

Sandmann, L. R., \& Plater, W. M. (2009). Leading the engaged institution. New Directions for Higher Education, 2009(147), 13-24.

Sandmann, L. R., Thornton, C. H., \& Jaeger, A. J. (2009). Institutionalizing community engagement in higher education: The first wave of Carnegie classified institution. New Directions for Higher Education, 2009(147), 1-112.

Stanton, T. K. (2008). New times demand new scholarship: Opportunities and challenges for civic engagement at research universities. Education, Citizenship and Social Justice, 3(1), $19-42$.

Stanton, T. K. (2012). New times demand new scholarship II: Research universities and civic engagement: Opportunities and challenges. Journal of Higher Education Outreach and Engagement, 16(4), 271-304.

Strand, K. J., Cutforth, N., Stoecker, R., Marullo, S., \& Donohue, P. (2003). Community-based research and higher education: Principles and practices. Hoboken, NJ: John Wiley \& Sons. 
Sturm, S. (2007). The architecture of inclusion: Interdisciplinary insights on pursuing institutional citizenship. Harvard Journal of Law and Gender, 30, 409-424.

Syracuse University. (n.d.). Faculty manual: 2.34. Areas of expected faculty achievement: Teaching, research, and service. Retrieve from http://provost.syr.edu/faculty-manual/234-areas-of-expected-faculty-achievement-teaching-research-and-service/

Tierney, W. G., \& Perkins, J. F. (2015). Beyond the ivory tower: Academic work in the $21^{\text {st }}$ century. In G. Shaker (Ed.), Faculty and the public good. New York, NY: Teacher College Press.

Tulane University. (2013). Academic review and engagement at Tulane University: A white paper for discussion. Retrieved from https://www.dropbox.com/s/065jymuepcp2ds0/ Academic-Review-and-Engagement-February-2013.pdf? $\mathrm{dl}=0$

University of North Carolina at Chapel Hill. (2010). Academic plan 2011: Reach Carolina. Retrieved from http://faccoun.unc.edu/files/2011/01/2010AcademicPlanPublicDraft.pdf

Warnick, C. (2007). Creating a new kind of university: Institutionalizing community-university engagement. Community Literacy Journal, 1(2).

Weerts, D. J., \& Sandmann, L. R. (2008). Building a two-way street: Challenges and opportunities for community engagement at research universities. Review of Higher Education, 32(1), 73-106.

Wergin, J. F. (2006). Elements of effective community engagement. S. L. Percy, N. L. Zimpher \& M. J. Brukhard (Eds.), Creating a new kind of university. Institutionalizing communityuniversity engagement. Bolton, MA: Anker.

White, B. P. (2016). Building an organizational structure that fosters blended engagement. In M. Post, E. Ward, N. Longo, \& J. Saltmarsh (Eds.), Publicly engaged scholars (pp. 232246). Sterling, VA: Stylus. 


\section{Authors}

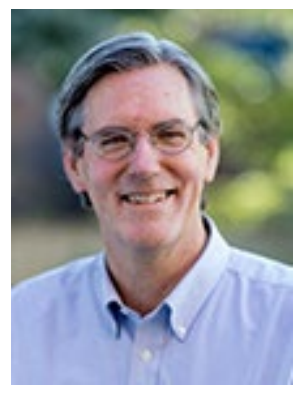

John Saltmarsh is Professor of Higher Education in the Department of Leadership in Education in the College of Education and Human Development at the University of Massachusetts, Boston. John publishes widely on community engaged teaching, learning, and research, and organizational change in higher education, including the co-edited book Publicly Engaged Scholars: Next Generation Engagement and the Future of Higher Education(2016). He is the co-author of the Democratic Engagement White Paper(2009) and Full Participation: Building the Architecture for Diversity and Public Engagement in Higher Education(2011). John is a Distinguished Engaged Scholar at the Swearer Center for Public Service at Brown University, where he leads the project in which the Swearer Center serves as the administrative partner with the Carnegie Foundation for elective Community Engagement Classification. He is also a Visiting Scholar with College Unbound in Providence, Rhode Island.

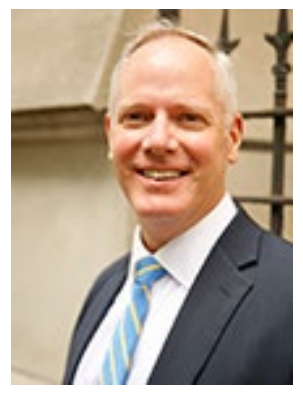

Michael Middleton is the Klara and Larry Silverstein Dean of the School of Education at Hunter College, City University of New York. He began his career as a high school mathematics teacher working with at-risk youth before earning a doctoral degree in Education and Psychology from the University of Michigan. His research focuses on the relation of classroom and cultural contexts on adolescent achievement motivation and well-being in diverse community settings locally, nationally and internationally. His research has received funding through the National Science Foundation. His scholarship includes his recent book Motivation to Learn: Transforming Classroom Culture to Support Student Achievement. At the University of New Hampshire he held the John and H. Irene Peters Professorship in Education and was a recipient of a Faculty Excellence in Teaching Award. Before coming to Hunter College, he was Dean of the College of Education and Human Development at University of Massachusetts Boston

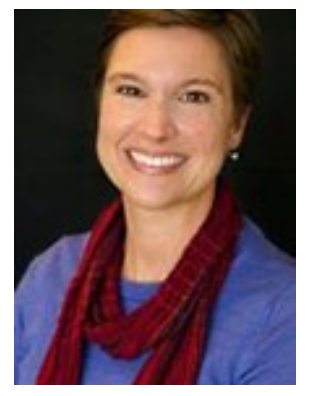

Melissa Quan, M.A. is Director of the Center for Faith and Public Life at Fairfield University where she has worked since 2002. As director, she leads the strategic growth and development of academic community engagement. Melissa completed her Master's in Education at Fairfield University with a concentration on service learning and civic education in 2005 and is currently pursuing a doctoral degree in Higher Education Administration at the University of Massachusetts Boston. Melissa served as interim Executive Director of Connecticut Campus Compact from 2008-2009 and later as a Research Fellow with Campus Compact's Community-Engaged Professionals project. Melissa is an alumnus of the Jesuit Volunteer Corps (1998-1999) and currently serves on the Board of Directors with RYASAP (Regional Adult and Youth Social Action Partnership). 